\title{
Anurofauna da floresta de restinga do Parque Estadual da Ilha do Cardoso, Sudeste do Brasil: composição de espécies e uso de sítios reprodutivos
}

\author{
Vivian Maria de Faria Nasser Vilela ${ }^{1}$, Ricardo Augusto Brassaloti ${ }^{1}$ \& Jaime Bertoluci ${ }^{1,2}$ \\ ${ }^{1}$ Departamento de Ciências Biológicas, Escola Superior de Agricultura “Luiz de Queiroz", \\ Universidade de São Paulo - USP, Av. Pádua Dias 11, CEP 13418-900, Piracicaba, SP, Brasil \\ ${ }^{2}$ Autor para correspondência: Jaime Bertoluci,e-mail: bertoluc@esalq.usp.br
}

VILELA, V.M.F.N., BRASSALOTI, R.A. \& BERTOLUCI, J. Anuran fauna of the restinga forest of the Parque Estadual da Ilha do Cardoso, Southeastern Brazil: species composition and breeding site utilization. Biota Neotrop. 11(1): http://www.biotaneotropica.org.br/v11n1/en/abstract?article+bn01611012011.

\begin{abstract}
The Parque Estadual da Ilha do Cardoso is of great concern to conservation because it includes several coastal ecosystems, like mangroves, sand dunes, restingas, and Atlantic Rainforest, all of them under human pressure since Brazil discovery. The anuran fauna of Brazilian restingas remains poorly known; the discovery of new species and the dificulties to determine the anurans reflect the rarity of studies in these areas. We provide here a updated list of amphibians from the restinga Forest of the Parque Estadual da Ilha do Cardoso. Our inventory was conducted from October 2005 and October 2007, totaling 25 two-days trips. Two methods were applied: visual encounter survey in a 10 ha permanent plot and visual and acoustic survey in nine sites used by anurans for reproduction. The anuran fauna of the study site is composed by 17 species belonging to the families Bufonidae (2 species), Craugastoridae (1), Hylidae (10), Leiuperidae (1), Leptodactylidae (2), and Microhylidae (1). Estimated species richness was 17.77-17.96, which suggests our sampling effort was enough to adequately sample the anuran assemblage present in the area. This richness can be considered high when compared to the richness of other restinga areas, especially those with less structured vegetation. The dominance of the family Hylidae is common to all neotropical localities. None species is included in the lists of endangered species from the state of São Paulo and Brazil, but Aparasphenodon bokermanni is considered Data Deficient by IUCN, and other three species (Dendrophryniscus leucomystax, Haddadus binotatus and Itapotihyla langsdorffii) have decreasing populations. This information reveals the importance of the restinga forest of Ilha do Cardoso to the conservation of anuran populations. A cluster analysis of 14 species that used nine breeding sites resulted in three groups, and the hydroperiod can be considered the major factor influencing the similarities among species. We conclude that preserving water bodies with diferent physiognomies is essential for conserving viable anuran populations. Keywords: Anurans, restinga forest, species inventory, conservation, Ilha do Cardoso State Park, Southeastern Brazil.
\end{abstract}

VILELA, V.M.F.N., BRASSALOTI, R.A. \& BERTOLUCI, J. Anurofauna da floresta de restinga do Parque Estadual da Ilha do Cardoso, Sudeste do Brasil: composição de espécies e uso de sítios reprodutivos. Biota Neotrop. 11(1): http://www.biotaneotropica.org.br/v11n1/pt/abstract?article+bn01611012011.

Resumo: O Parque Estadual da Ilha do Cardoso é uma área de grande importância para a conservação, pois abriga diferentes ecossistemas costeiros, como manguezais, dunas, restingas e mata atlântica de encosta, que, historicamente, estiveram sob forte pressão antrópica. A identificação duvidosa e a descoberta de novas espécies da anurofauna em ambientes costeiros, evidencia a escassez de estudos nessas regiões. Inventariamos a anurofauna da floresta de restinga do Parque Estadual da Ilha do Cardoso entre outubro de 2005 e outubro de 2007, por meio de 25 viagens mensais de dois dias de duração. Foram utilizados dois métodos: procura visual ativa em uma parcela permanente de 10 ha e procura visual e auditiva em nove sítios de reprodução. A anurofauna da área de estudo é composta por 17 espécies pertencentes às famílias Bufonidae (2 espécies), Craugastoridae (1), Hylidae (10), Leiuperidae (1), Leptodactylidae (2) e Microhylidae (1). A riqueza estimada foi de 17,77-17,96, o que mostra que nosso esforço amostral foi suficiente para registrar praticamente toda a anurofauna presente nessa formação de restinga. Essa riqueza pode ser considerada elevada quando comparada à de outras áreas de restinga, principalmente aquelas dotadas de vegetação menos estruturada. O predomínio da família Hylidae é característico de todas as localidades da região neotropical. Nenhuma espécie acha-se incluída nas listas de espécies ameaçadas de extinção do estado de São Paulo e do Brasil, mas Aparasphenodon bokermanni é considerada pouco conhecida ("Data Deficient") pela IUCN, e outras três espécies (Dendrophryniscus leucomystax, Haddadus binotatus e Itapotihyla langsdorffii) apresentam populações em declínio. Essas informações revelam a importância da floresta de restinga da Ilha do Cardoso para a manutenção de populações de anuros. Uma análise de agrupamento de 14 espécies que utilizaram nove sítios reprodutivos evidenciou três grupos, sendo o hidroperíodo o principal fator na determinação das similaridades. Conclui-se que a preservação de corpos d'água com diferentes fisionomias é essencial para a conservação de populações viáveis de anuros.

Palavras-chave: Anuros, floresta de restinga, inventário, conservação, Parque Estadual da Ilha do Cardoso, Sudeste do Brasil. 


\section{Introdução}

Ao longo da baixada litorânea, sobre substratos arenosos, a Mata Atlântica assume a fisionomia de vegetação de restinga. Esse tipo vegetacional, de estrutura bastante variável, recobre cerca de $80 \%$ da costa brasileira (Lacerda et al. 1993), representando um dos conjuntos de ecossistemas mais amplos do Brasil, ocorrendo desde o sul até o norte, com diversas áreas fragmentadas ao longo de sua distribuição no litoral (Teixeira 2001). A restinga é um ambiente geologicamente recente (Freire 1990) e possui uma vegetação característica devido a uma combinação de fatores físicos e químicos, como elevadas temperaturas e salinidade, grande deposição de salsugem e alta exposição à luminosidade (e.g. Franco et al. 1984). Nas imediações de corpos d'água, a vegetação torna-se mais densa, assumindo a fisionomia de floresta (Araujo et al. 1998). A família Bromeliaceae é bastante representada nesse ambiente, sendo importante especialmente para os anfíbios, principalmente pela capacidade de armazenamento de água em seu tubo central e nas axilas das folhas (Rocha et al. 1997). Diversos anfíbios utilizam as bromeliáceas como locais de forrageio, reprodução e refúgio contra predadores (Britto-Pereira et al. 1988a, Peixoto 1995, Oliveira \& Rocha 1997, Schineider \& Teixeira 2001, Alves-Silva \& Silva 2009).

Tendo em vista a enorme extensão desta formação costeira (Lacerda et al. 1993), estudos de longa-duração abrangendo pelo menos um ano, são ainda muito escassos, mesmo quando são considerados aqueles desenvolvidos na Restinga de Barra de Maricá (Britto-Pereira et al. 1988a, b), na Restinga de Jurubatiba (Van Sluys et al. 2004) e na Restinga de Marambaia (Silva et al. 2008), no Estado do Rio de Janeiro, e no Parque Estadual da Ilha do Cardoso (Bertoluci et al. 2007a, presente trabalho) e na Estação Ecológica Juréia-Itatins, Núcleo Arpoador (Narvaes et al. 2009), no Estado de São Paulo. A lista de anuros fornecida por Pombal Jr. \& Gordo (2004) para a Estação Ecológica Juréia-Itatins (região do Rio Verde) inclui ambientes além da restinga, não representando, portanto, uma taxocenose típica dessa formação. A relativa hostilidade dos ambientes de restinga à ocorrência de anfíbios (Van Sluys et al. 2004), pode ser evidenciada pela baixa riqueza de espécies encontrada nas localidades citadas acima. Essa baixa riqueza torna-se mais evidente quando comparada à de taxocenoses da Mata Atlântica de encosta, com a qual compartilha muitas espécies em escala regional e biogeográfica (Van Sluys et al. 2004, Bertoluci et al. 2007a).

Este trabalho teve como objetivo o inventário da anurofauna da floresta de restinga do Parque Estadual da Ilha do Cardoso (SP) e o estudo da distribuição espacial das espécies em ambientes reprodutivos monitorados durante 25 meses consecutivos.

\section{Material e Métodos}

\section{1. Área de estudo}

O Parque Estadual da Ilha do Cardoso (PEIC) situa-se na poção norte da ilha de mesmo nome, localizada no extremo sul do litoral do estado de São Paulo, município de Cananéia (25ㅇ $03^{\prime}-25^{\circ} 18^{\prime} \mathrm{S}$ e $47^{\circ} 53^{\prime}-48^{\circ} 05^{\prime} \mathrm{W}$ ) (Figura 1). A Ilha possui aproximadamente 22.500 ha de superfície, e abriga quatro ecossistemas principais muito distintos: dunas, floresta ombrófila densa (sensu lato), manguezais e floresta de restinga (Noffs \& Baptista-Noffs 1982). O relevo é predominantemente montanhoso, com altitudes superiores a $800 \mathrm{~m}$. Como reflexo das condições de umidade e fertilidade do solo, a vegetação sobre a restinga é composta por mosaicos vegetacionais com diversas fisionomias, sob a influência marinha e fluvio-marinha (Araújo \& Lacerda 1987). Quanto mais distantes do oceano, maior é a complexidade desses ecossistemas, sendo a composição florística determinada pelas condições edáficas, topografia, profundidade do lençol freático e também pelas diferentes interrelações biológicas entre os indivíduos presentes (Araújo \& Lacerda 1987, Mantovani 2003). A floresta de restinga baixa é composta por muitas espécies de Myrtaceae, além de espécies de Aquifoliaceae, Malpighiaceae, Theaceae, Clusiaceae, Fabaceae e Lauraceae (Mantovani 2003). Sobre os cordões arenosos, em solos bem drenados, tem-se uma floresta alta de restinga (Araújo \& Lacerda 1987, Mantovani 2003). O clima é do tipo Af de Köppen, megatérmico superúmido sem estação seca definida e com excesso de chuvas no verão (Funari et al. 1987). A temperatura média anual na Ilha do Cardoso é de $22,3{ }^{\circ} \mathrm{C}$, e a precipitação média anual de $2216 \mathrm{~mm}$ (Walter et al.1975).

\section{Métodos de amostragem}

A amostragem da anurofauna da restinga foi realizada pela aplicação de dois métodos principais: a procura visual ativa (Crump $\&$ Scott 1994) em uma parcela permanente de 10 ha (Bertoluci et al. 2007a) e a procura em ambientes de reprodução (Scott \& Woodward 1994), esta última aplicada em conjunto com uma terceira técnica, a de transectos auditivos (Zimmerman 1994), realizados em nove diferentes ambientes de reprodução utilizados pelas espécies (Figura 2). Uma breve caracterização dos ambientes monitorados é apresentada na Tabela 1. Também foram inclusos registros não sistemáticos das espécies encontradas nas trilhas de acesso aos ambientes visitados.

A procura visual foi aplicada durante o dia, uma vez por mês, entre outubro de 2005 e outubro de 2006, percorrendo em dois dias consecutivos um transecto de aproximadamente $5.000 \mathrm{~m}$ ao longo das linhas que delimitam sub-parcelas de $20 \times 20 \mathrm{~m}$ na parcela permanente (Figura 2a). O trajeto foi feito por dois pesquisadores, resultando em um esforço amostral mensal de 240 horas/pessoa nos 12 meses de amostragem. Em uma faixa de 1,5 m ao longo do transecto, os micro-hábitats comumente utilizados pelos anuros (e.g. serapilheira, troncos caídos, fendas de rochas e tubos de bromeliáceas) foram vasculhados em busca de indivíduos não ativos durante o dia. Os métodos utilizados nos locais de reprodução, fora da parcela permanente, estenderam-se até outubro de 2007, sendo realizados no período noturno, entre as horas de maior atividade reprodutiva (19:00 - 00:00 horas), totalizando cerca de 250 horas/pessoa em 25 meses de amostragem.

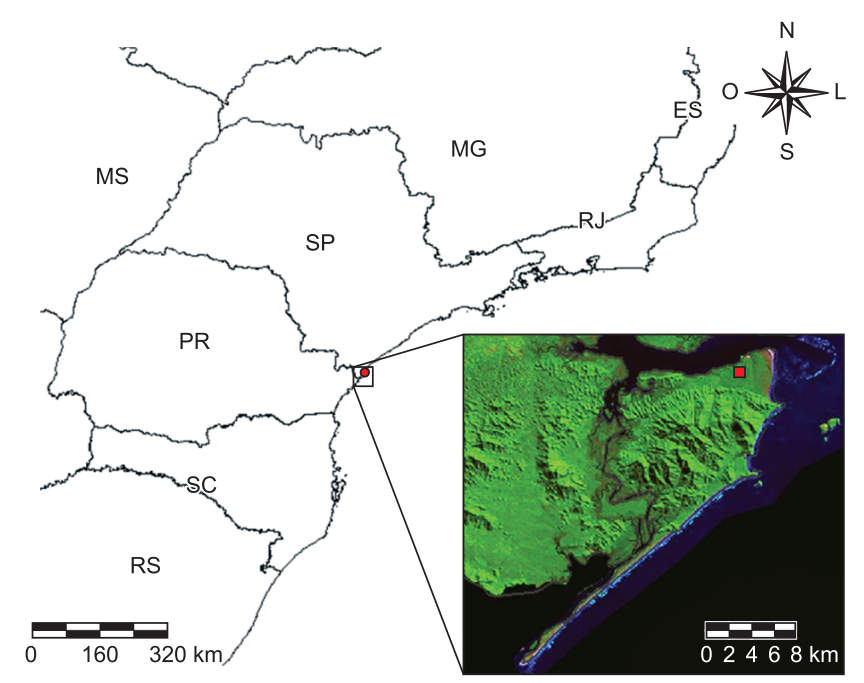

Figura 1. Localização do Parque Estadual da Ilha do Cardoso no Estado de São Paulo, Sudeste do Brasil. O quadrado vermelho representa o Parque.

Figure 1. Location of the Parque Estadual da Ilha do Cardoso in São Paulo State, Southeastern Brazil. The red square represents the Parque. 
As vocalizações das espécies foram gravadas com o auxílio de um gravador micro cassete Panasonic ${ }^{\circledR}$ (modelo RQ-L30), de um gravador digital portátil e de um gravador digital profissional Marantz PMD-660 com microfone direcional Senheiser MKH 60, para auxiliar na identificação das espécies em laboratório, que foi feita a partir de comparações com espécimes depositados em coleções herpetológicas (CFBH e MZUSP) e consulta a especialistas. A nomenclatura adotada está de acordo com Frost (2010). Os indivíduos coletados (licença IBAMA $n^{\circ} 430 / 05$ ) foram mortos em atmosfera saturada de $\mathrm{CO}_{2}$ (de acordo com a resolução $\mathrm{N}^{\circ}$. 714 de 20 de junho de 2002 da CFMV), fixados em formalina $10 \%$ e preservados em álcool $70 \%$. Esses exemplares foram depositados na coleção herpetológica do Laboratório de Zoologia de Vertebrados do Departamento de Ciências Biológicas da Escola Superior de Agricultura Luiz de Queiroz, Universidade de São Paulo (acrônimo VESALQ) (Apêndice 1).

\section{Análise de dados}

Para avaliar a eficiência da amostragem de anuros na restinga do PEIC, foram confeccionadas curvas de rarefação de espécies (sensu Gotelli \& Colwell 2001) a partir da matriz de dados de presença e ausência mensal das espécies amostradas pelo conjunto de métodos, utilizando o Programa EstimateS, versão 7.5.2 (Colwell 2005), com 500 aleatorizações e sem reposição de amostras. Também foi estimada a riqueza de espécies utilizando os estimadores não-paramétricos Bootstrap e Jacknife 1 (Santos 2003).

\section{Resultados e Discussão}

\section{Composição de espécies}

$\mathrm{Na}$ restinga do PEIC, foram encontradas 17 espécies de anuros pertencentes às famílias Hylidae (10 espécies), Bufonidae (2), Leptodactylidae (2), Craugastoridae (1), Leiuperidae (1) e Microhylidae (1) (Figura 3). Seguem, abaixo, comentários sucintos sobre as espécies registradas neste inventário.

\section{FAMÍLIA BUFONIDAE}

\section{Dendrophryniscus leucomystax Izecksohn, 1968 (Figura 3a)}

Essa espécie ocorre em áreas de baixa altitude dentro do Domínio Morfoclimático Tropical Atlântico e pode ser encontrada na serapilheira de florestas primárias e secundárias e em solos encharcados na planície costeira dos Estados do Rio de Janeiro, São Paulo, Paraná e Norte de Santa Catarina (IUCN 2010). Reproduz-se em poças formadas pela água da chuva no chão da floresta (Izecksohn 1968, Izecksohn \& Cruz 1972). Registros dessa espécie quase sempre estão associados a unidades de conservação ou em áreas bem-preservadas (IUCN 2010). Na área de estudo foram observados indivíduos em atividade de vocalização em bromeliáceas terrestres e na serapilheira na restinga alta da parcela permanente. Picos de atividade reprodutiva foram constatados antes
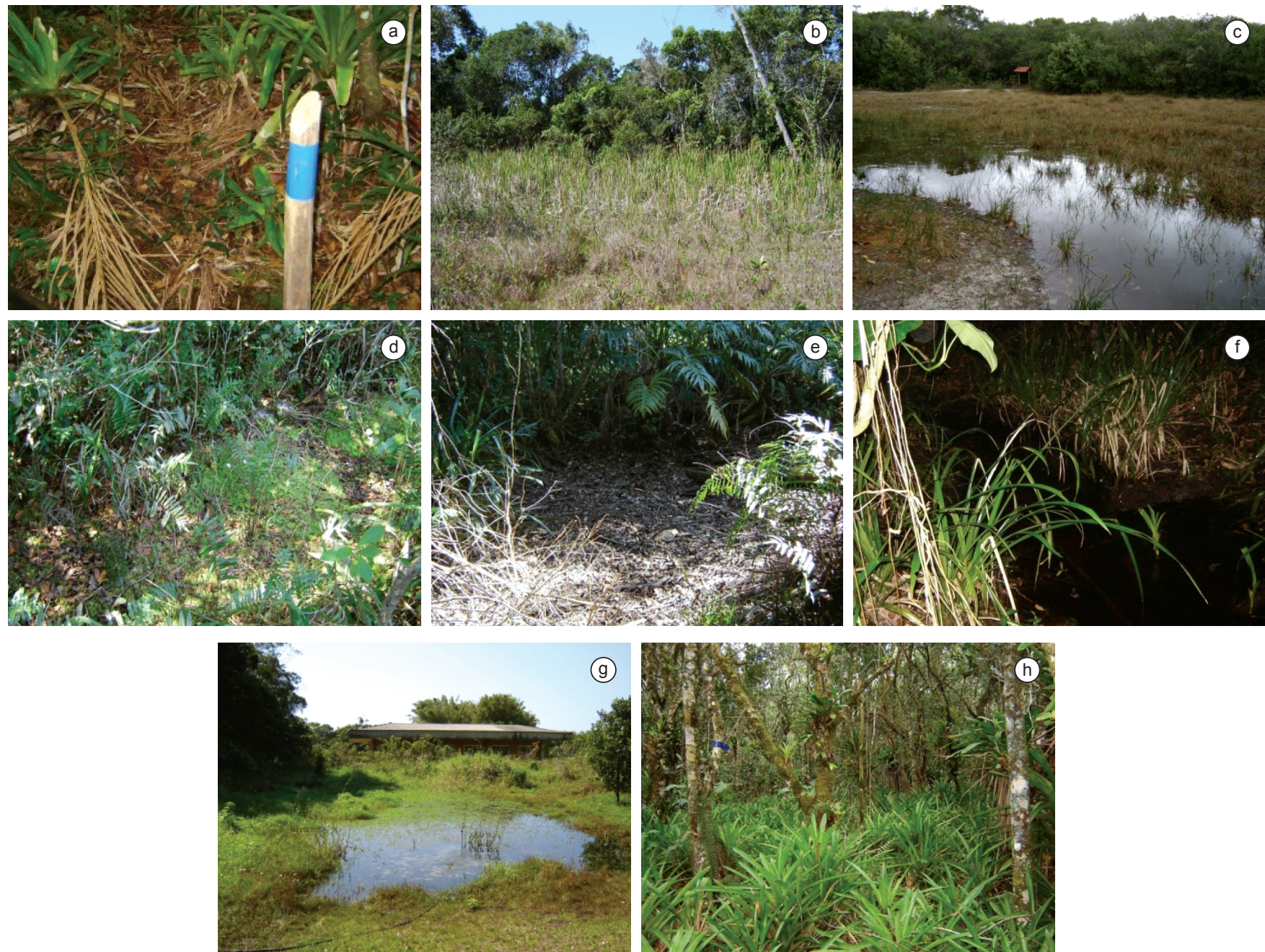

Figura 2. Ambientes amostrados no Parque Estadual da Ilha do Cardoso, Sudeste do Brasil: a) parcela permanente; e b-j) sítios reprodutivos dos anfíbios.

Figure 2. Habitats sampled in the Parque Estadual da Ilha do Cardoso, Southeastern Brazil: a) permanent plot; and b) breeding sites of amphibians. 
do crepúsculo em dias chuvosos de novembro a março. Também foram observados indivíduos executando tanatose, com pernas esticadas e enrijecimento de todo o corpo quando molestados pelo pesquisador, um comportamento defensivo conhecido para outras espécies de anuros de serapilheira (Bertoluci et al. 2007b).

\section{Rhinella ornata (Spix, 1824) (Figura 3b)}

No Brasil apresenta distribuição ao longo da Mata Atlântica do Sul do Estado do Espírito Santo, passando pelo Rio de Janeiro (exceto na porção noroeste) e São Paulo até o norte do Paraná (Baldissera Jr. et al. 2004). Foi encontrada no PEIC em grandes agregações reprodutivas em ambientes temporários de áreas abertas e poças dentro da restinga durante os meses de maior pluviosidade. Recentemente foi desmembrada do complexo de espécies do grupo crucifer. Porem, segundo Thomé et al. (2010) o antigo complexo $R$. crucifer pode ter sido excessivamente dividido. A única espécie que de fato, com base em DNA mitocondrial, forma um grupo monofilético é $R$. henseli (Lutz, 1934). E considerando também a proximidade com áreas para as quais é relatada a ocorrência de $R$. abei (Baldissera, Caramaschi \& Haddad, 2004) no litoral norte do Paraná (e.g. Guaraqueçaba; Baldissera Jr. et al. 2004), os nomes $R$. abei e $R$. ornata podem estar sendo aplicados à mesma espécie.

\section{FAMÍLIA CRAUGASTORIDAE}

\section{Haddadus binotatus (Spix, 1824) (Figura 3c)}

Ocorre do sul Bahia até o Norte do Rio Grande do Sul, apresentando ampla distribuição nas áreas de Mata Atlântica do Sudeste e Sul do Brasil (IUCN 2010, Frost 2010). Espécie bastante comum, frequentemente observada em áreas de matas primárias e secundárias, mas nunca em áreas abertas ou muito antropizadas. Pode ser encontrada ativa na serapilheira durante o dia, tanto forrageando quanto se reproduzindo; apresenta desenvolvimento direto a partir de ovos terrestres depositados na serapilheira (Heyer et al. 1990, Dixo \& Verdade 2006, Silva-Soares et al.2010). $\mathrm{Na}$ Ilha do Cardoso foi observada somente na área de restinga alta onde localiza-se a parcela permanente, geralmente na serapilheira e em tubos de bromeliáceas terrestres, destacando-se a ocorrência de muitos jovens nos meses de janeiro a março.

\section{FAMÍLIA HYLIDAE}

\section{Aparasphenodon bokermanni Pombal, 1993 (Figura 3d)}

Apenas dois indivíduos foram encontrados na área de estudo, um deles dentro da axila de uma bromeliácea na parcela permanente, durante o dia, e outro sobre uma folha de bromeliácea a $50 \mathrm{~cm}$ do chão, no período noturno, porem não foi observado o uso de bromeliáceas para a reprodução. Apenas um espécime foi coletado na Estação Ecológica da Juréia-Itatins (SP) (Pombal Jr. \& Gordo 2004), sua localidade-tipo, sendo também conhecida do município de Guaramirim, Santa Catarina (Woehl Jr. \& Woehl 2003). Sua biologia, distribuição geográfica e estado de conservação permanecem quase que desconhecidos.

\section{Dendropsophus berthalutzae (Bokermann, 1962) (Figura 3e)}

Os machos dessa espécie vocalizam sobre arbustos ou vegetação rasteira associados a corpos d'água em floresta secundária ou próximo de brejos, sendo também encontrados em alagados em áreas abertas ou muito alteradas (IUCN 2010). As fêmeas depositam seus ovos sobre folhas da vegetação marginal de corpos d'água lênticos e temporários, com ou sem troca constante da água, nos quais as larvas caem e se desenvolvem até a metamorfose (Izecksohn \& Carvalho-e-Silva 2001). Essa espécie é encontrada na planície costeira da Serra do Mar até $1200 \mathrm{~m}$ de altitude, a partir do sul do Espírito Santo até sul de Santa Catarina (IUCN 2010). Na Ilha do Cardoso, foram avistados indivíduos vocalizando em arvoretas e taboas (Tipha sp.) a 1,5 m de altura da superfície da água de poças temporárias localizadas dentro e na borda da floresta de restinga.

\section{Dendropsophus cf. decipiens (Figura 3f-g)}

Dendropsophus decipiens (A. Lutz, 1925) apresenta ampla distribuição pela faixa litorânea do Brasil, do Maranhão a São Paulo, com a Ilha do Cardoso representando seu extremo sul de distribuição, provavelmente representando um complexo de espécies (IUCN 2010). Ocorre em uma grande variedade de habitats, incluindo áreas abertas alteradas ou não, restingas, florestas primárias e secundárias (IUCN 2010). Os ovos são postos sobre folhas da vegetação marginal de corpos d'água temporários e permanentes, onde os girinos se desenvolvem e sofrem metamorfose (Silva et al. 2008). Não pudemos determinar com segurança a identidade dessa espécie devido ao grande polimorfismo que ocorre no táxon e sua difícil diagnose em relação a outras espécies proximamente relacionadas do grupo microcephalus (D. branneri (Cochran, 1948), D. haddadi (Bastos \& Pombal, 1996) e D. oliveirai (Bokermann, 1963)), muitas vezes ocorrendo em simpatria (Bastos \& Pombal 1996, Izecksohn et al. 2001).

\section{Hypsiboas albomarginatus (Spix, 1824) (Figura 3h)}

Ocorre na baixada litorânea em altitudes de até 380 m (Lutz 1973), desde Pernambuco até Santa Catarina (Frost 2010). Trata-se de uma espécie comum em sua área de ocorrência, apresentando grandes agregações reprodutivas e picos de atividade associados aos períodos chuvosos no verão (Bertoluci \& Rodrigues 2002a). Apresenta quatro tipos diferentes de comunicação visual associadas ao seu comportamento reprodutivo

Tabela 1. Características físicas dos nove corpos d’água estudados no Parque Estadual da Ilha do Cardoso (SP).

Table 1. Physical characteristics of the nine water bodies studied in the Parque Estadual da Ilha do Cardoso (SP).

\begin{tabular}{|c|c|c|c|c|}
\hline $\begin{array}{l}\text { Corpos } \\
\text { d'água }\end{array}$ & $\begin{array}{c}\text { Localização } \\
\text { geográfica }\end{array}$ & Hidroperíodo & $\begin{array}{c}\text { Área aprox. } \\
\left(\mathbf{m}^{2}\right)\end{array}$ & $\begin{array}{l}\text { Tipo de vegetação } \\
\text { circundante }\end{array}$ \\
\hline Sítio 1 & $20^{\circ} 52^{\prime} 63^{\prime \prime} \mathrm{S}$ e $72^{\circ} 24^{\prime} 19^{\prime \prime} \mathrm{W}$ & Temporário & 28 & Floresta de restinga baixa \\
\hline Sítio 2 & $20^{\circ} 49^{\prime} 58^{\prime \prime} \mathrm{S}$ e $72^{\circ} 23^{\prime} 71^{\prime \prime} \mathrm{W}$ & Temporário & 1500 & Floresta de restinga baixa \\
\hline Sítio 3 & $20^{\circ} 48^{\prime} 79^{\prime \prime} \mathrm{S}$ e $72^{\circ} 23^{\prime} 51^{\prime \prime} \mathrm{W}$ & Temporário & 150 & Arbustiva-arbórea \\
\hline Sítio 4 & $20^{\circ} 50^{\prime} 70^{\prime \prime} \mathrm{S}$ e $72^{\circ} 24^{\prime} 05^{\prime \prime} \mathrm{W}$ & Temporário & 15 & Floresta de restinga baixa, alta densidade de bromeliáceas \\
\hline Sítio 5 & $20^{\circ} 54^{\prime} 48^{\prime \prime} \mathrm{S}$ e $72^{\circ} 24^{\prime} 11^{\prime \prime} \mathrm{W}$ & Permanente & 50 & Floresta de restinga baixa \\
\hline Sítio 6 & $20^{\circ} 54^{\prime} 48^{\prime \prime} \mathrm{S}$ e $72^{\circ} 24^{\prime} 11^{\prime \prime} \mathrm{W}$ & Permanente & 79 & Floresta de restinga baixa \\
\hline Sítio 7 & $20^{\circ} 52^{\prime} 07^{\prime \prime} \mathrm{S}$ e $72^{\circ} 24^{\prime} 24^{\prime \prime} \mathrm{W}$ & Permanente & 113 & Herbácea-Arbustiva \\
\hline Sítio 8 & $20^{\circ} 50^{\prime} 31^{\prime \prime} \mathrm{S}$ e $72^{\circ} 23^{\prime} 79^{\prime \prime} \mathrm{W}$ & - & 150 & Floresta de restinga baixa com alta densidade de bromeliáceas \\
\hline Sítio 9 & $20^{\circ} 48^{\prime} 13^{\prime \prime} \mathrm{S}$ e $72^{\circ} 23^{\prime} 17^{\prime \prime} \mathrm{W}$ & - & 150 & Floresta de restinga alta com alta densidade de bromeliáceas \\
\hline
\end{tabular}


(Hartmann et al. 2005) e um complexo comportamento de corte e disputa com machos rivais (Giasson \& Haddad 2006). Na área de estudo foram observados machos vocalizando sobre as folhas de taboa (Typha sp.) em uma área de brejo situada entre uma estrada e a floresta de restinga e, com menor frequência, na vegetação de alagados temporários. Bokermann (1967), além de descrever seu canto de anúncio, observou machos vocalizando também no chão e sobre plantas flutuantes.
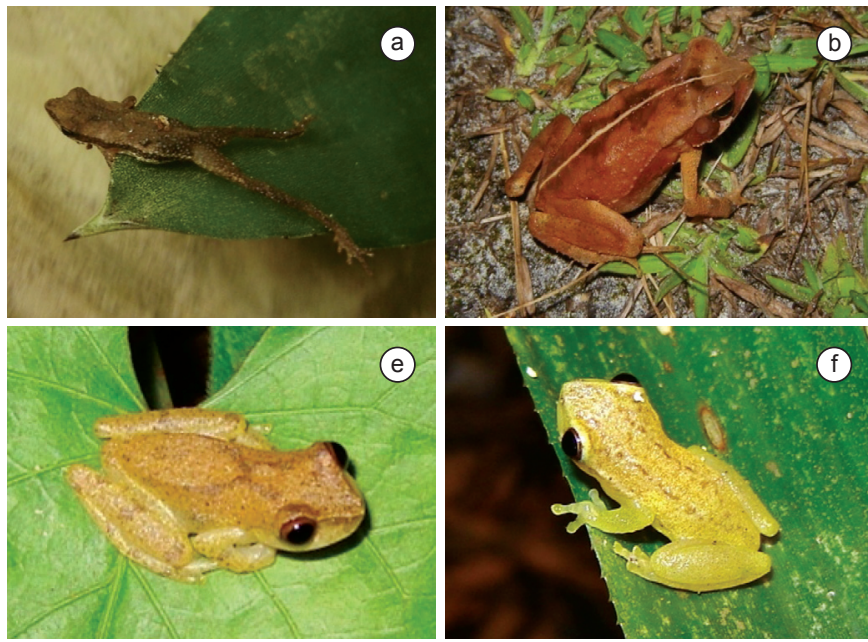

( )
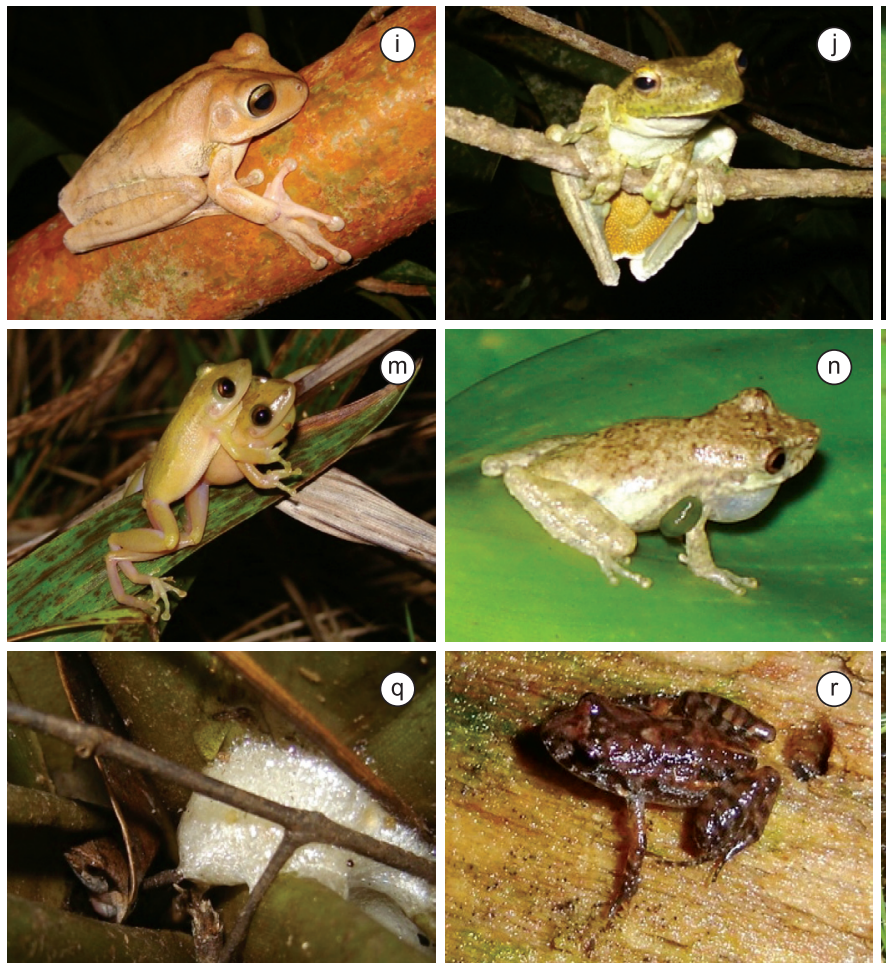

Hypsiboas faber (Wied-Neuwied, 1821) (Figura 3i)

Essa espécie apresenta ampla distribuição geográfica, ocorrendo em Misiones, na Argentina, no sudeste do Paraguai, nos estados brasileiros do Rio de Janeiro, Espírito Santo, Minas Gerais, Rio Grande do Sul, Paraná, Santa Catarina, São Paulo e Bahia (Frost 2010). Ocorre também em ambientes muito alterados (IUCN 2010). Na Ilha do Cardoso, foram observados machos vocalizando sobre galhos de árvores, no chão e dentro da lagoa

Figura 3. Espécies de anfíbios anuros encontradas no Parque Estadual da Ilha do Cardoso, SP, na área de restinga estudada, entre outubro de 2005 e outubro de 2007. a) Dendrophryniscus leucomystax; b) Rhinella ornata; c) Haddadus binotatus; d) Aparasphenodon bokermanni; e) Dendropsophus berthalutzae; f) Dendropsophus cf. decipiens; g) outro padrão de coloração de Dendropsophus cf. decipiens; h) Hypsiboas albomarginatus; i) H. faber; j) Itapotihyla langsdorffi; k) S. argyreornatus; 1) Scinax sp.1 (aff. alter); m) interação agonística entre machos de Scinax sp.1 (aff. alter); n) Scinax sp.2 (aff. perpusillus); o) Scinax sp.3 (gr. rizibilis); p) Physalaemus spiniger; q) ninho de espuma de P. spiniger em bromeliácea; r) Leptodactylus bokermanni; s) L. latrans; e t) Chiasmocleis leucosticta. Fotos: VMFNV (d-f, h-i, k-m, o-p) e RAB (a-c, g, j, n, q-r).

Figure 3. Amphibian anuran species found at resting formation on Ilha do Cardoso State Park, SP, between October 2005 and October 2007. a) Dendrophryniscus leucomystax; b) Rhinella ornata; c) Haddadus binotatus; d) Aparasphenodon bokermanni; e) Dendropsophus berthalutzae; f) Dendropsophus cf. decipiens; g) Another color pattern of Dendropsophus cf. decipiens; h) Hypsiboas albomarginatus; i) H. faber; j) Itapotihyla langsdorffi; k) S. argyreornatus; 1) Scinax sp.1 (aff. alter); m) Agonistic behavior in males Scinax sp.1 (aff. alter); n) Scinax sp.2 (aff. perpusillus); o) Scinax sp.3 (gr. rizibilis); p) Physalaemus spiniger; q) Foam nest of $P$. spiniger in a bromeliad; r) Leptodactylus bokermanni; s) L. latrans; and t) Chiasmocleis leucosticta. Photos: VMFNV (d-f, h-i, k-m, o-p) and RAB (a-c, g, j, n, q-r). 
temporária localizada em área aberta, coberta por gramíneas e margeada por floresta de restinga. Ovos e girinos foram vistos dentro das bacias construídas pelos machos, como descrito por Martins \& Haddad (1988), nos períodos de maior atividade reprodutiva durante a estação chuvosa (novembro a fevereiro). Não foram encontradas grandes agregações reprodutivas comuns para essa espécie (Bertoluci \& Rodrigues 2002a), possivelmente refletindo certo grau restritivo dos corpos d'água presentes na restinga (e.g. alta salinidade e baixo $\mathrm{pH}$ ).

\section{Itapotihyla langsdorffii (Duméril \& Bibron, 1841) (Figura 3j)}

Na restinga da Ilha do Cardoso, indivíduos dessa espécie foram encontrados vocalizando em poças temporárias e permanentes localizadas dentro da floresta, em áreas de clareiras ou na borda da mata apenas em outubro e novembro de 2005. Apresenta ampla distribuição geográfica na floresta atlântica, ocorrendo desde Sergipe até o Rio Grande do Sul, alcançando áreas do nordeste da Argentina e leste do Paraguai em sua porção mais a oeste (Arzabe \& Loebmann 2006, Frost 2010), podendo ser encontrada em altitudes de até 700 m; possui baixa tolerância a alterações antrópicas (IUCN 2010).

\section{Scinax argyreornatus (Miranda-Ribeiro, 1926) (Figura 3k)}

Essa espécie é conhecida das regiões costeiras do Brasil, da Bahia até o Sul de Santa Catarina, em altitudes de até $1100 \mathrm{~m}$ (Silvano \& Pimenta 2001, IUCN 2010). Ocorre tanto em matas densas como em matas mais abertas, como na restinga alta, sendo também encontrada em plantações de cacau no Espírito Santo, sempre em grandes agregações reprodutivas (Izecksohn et al. 2001, Teixeira \& Vrcibradic 2004). Scinax argyreornatus é uma espécie comumente encontrada sobre a vegetação em poças permanentes e temporárias do interior de florestas de baixada, onde se reproduz, apresentando atividade de vocalização de setembro a março (Carvalho-e-Silva \& Carvalho-e-Silva 1998). Na Ilha do Cardoso, foram observados indivíduos jovens e adultos em grande número no período noturno durante a estação chuvosa, sobre folhas de bromeliáceas e arvoretas em áreas alagadas.

Scinax sp.1 (aff. alter) (Figura 31-m)

As espécies de Scinax do grupo alter ocorrem frequentemente associadas à baixada litorânea e partes baixas da Floresta Atlântica,, com registros de Pernambuco a Santa Catarina (Pombal Jr. \& Gordo 2004). Sua ampla distribuição geográfica sugere que possivelmente trata-se de um grupo de espécies sendo tratadas sob a mesma denominação (IUCN 2010). Na Ilha do Cardoso, foi observado um grande número de machos vocalizando sobre folhas e galhos de árvores localizadas na margem de uma poça temporária, a até $1,70 \mathrm{~m}$ acima do chão. A Figura 31 mostra uma interação agonística entre dois machos surpreendidos em uma posição semelhante à de amplexo e que, após cerca de $60 \mathrm{~s}$ de observação, caíram da folha de gramínea sobre a qual foram encontrados. Esta espécie foi identificada como Scinax cuspidatus em Bertoluci et al. (2007a). Tanto $S$. alter quanto $S$. cuspidatus passam por revisão, sendo passível de mudança o táxon presente na área (Nunes 2008).

\section{Scinax sp.2 (aff. perpusillus) (Figura 3n)}

Os machos de S. perpusillus (Lutz \& Lutz, 1939) são territoriais e bromelígenos (Peixoto 1995), vocalizando a partir de bromeliáceas terrestres ou epifítas; durante o amplexo, os ovos são depositados na água acumulada nas axilas ou no tanque central, onde os girinos se desenvolvem (Oliveira \& Navas 2004, Alves-Silva \& Silva 2009). Contudo, cabe ressaltar que há um complexo de espécies sendo tratado sob a mesma denominação ou muitas vezes como grupo $S$. perpusillus (Silva \& Alves-Silva 2008). A distribuição do grupo S. perpusillus, na configuração válida atualmente, inclui áreas da Floresta Atlântica, da baixada litorânea a serras e planalto, do Espírito Santo a São Paulo, alcançando Santa Catarina (Peixoto 1987, Alves-Silva \& Silva 2009). Esta espécie foi adicionada à lista fornecida por Bertoluci et al. (2007a).

\section{Scinax sp.3 (gr. "rizibilis") (Figura 3o)}

Apenas dois indivíduos dessa espécie foram encontrados durante o estudo, sendo o primeiro no período diurno, abrigado na axila da Quesnelia arvensis, e o segundo no período noturno vocalizando a $1,5 \mathrm{~m}$ de altura, sobre folha de bromeliácea epífita, em um ambiente aquático temporário. Sua vocalização é semelhante à de $S$. rizibilis, porém com canto mais curto (menos notas multipulsionadas) e notas com menos pulsos; chegamos a essa conclusão após comparação dos espectrogramas gerados a partir de gravações em campo e de outras disponíveis na literatura (Haddad et al. 2005). Apresenta também algumas diferenças morfológicas (e.g. maior comprimento rostro-cloacal dos machos e barras da região inguinal diferentes das de $S$. rizibilis), não sendo possível a determinação segura dos indivíduos coletados.

\section{FAMÍLIA LEIUPERIDAE}

\section{Physalaemus spiniger (Miranda-Ribeiro, 1926) (Figura 3p-q)}

Esta espécie típica de áreas de restinga e Floresta Atlântica ocorre em áreas de baixas altitudes por toda a planície litorânea, da porção Nordeste do Estado de São de Paulo até norte da Baia de Paranaguá, no Paraná (Haddad \& Pombal 1998, IUCN 2010). Na lha do Cardoso, foram observados machos vocalizando e ninhos de espuma dentro de axilas de bromeliáceas e na serapilheira úmida próximo a poças temporárias, na borda e interior da restinga (Figura 3q), como relatado por Haddad \& Pombal (1998). Contudo, também foram encontrados girinos desenvolvendo-se em tubos e axilas de bromeliáceas terrestres, fato não observado no trabalho citado anteriormente, o que significa que essa espécie pode ser considerada bromelígena sensu Peixoto (1995).

\section{FAMÍLIA LEPTODACTYLIDAE}

\section{Leptodactylus bokermanni Heyer, 1973 (Figura 3r)}

Espécie típica de borda de florestas e áreas abertas próximo a fragmentos, os machos comumente vocalizam no solo sob a vegetação no final da tarde, podendo permanecer ativos durante dias nublados. Essa espécie também deposita seus ovos em ninhos de espuma, porém dentro de pequenas tocas no solo, onde os girinos desenvolvem-se até a metamorfose, sobrevivendo apenas com a reserva de vitelo (Heyer 1973). Há certa discordância se os girinos da descrição original pertencem realmente a essa espécie, de forma que a diversidade do grupo ainda é subestimada, com grande ocorrência de espécies crípticas (Kokubum 2008). Ocorre no sudeste brasileiro, nos estados de Minas Gerais, Rio de Janeiro, São Paulo, Paraná e Santa Catarina (Frost 2010), com sua localidade-tipo distante apenas $40 \mathrm{~km}$ da área de estudo. Encontrada em atividade durante o dia até as primeiras horas da noite, habitando o solo de florestas primárias e secundárias, clareiras, bordas da mata além de áreas alteradas. Esta espécie foi tratada erroneamente como L. marmoratus em Bertoluci et al. (2007a), porém é possível que as duas ocorram em sintopia, como é conhecido para outras localidades da Mata Atlântica (Angulo et al. 2003), em outros ambientes que não os estudados, uma vez que foram ouvidos e não gravados tipos de cantos sutilmente diferentes próximo a áreas de transição entre a restinga e a floresta ombrófila. 
Leptodactylus latrans (Steffen, 1815) (Figura 3s)

A espécie é noturna e encontrada em diversos ambientes, comumente em corpos de água lênticos em meio às gramíneas (Loebmann 2005, Deiques et al. 2007). Sua desova é depositada em ninho de espuma e os girinos formam grandes cardumes após a eclosão. A fêmea permanece nas proximidades e protege a prole (Vaz-Ferreira \& Gerhau 1975), fato também observado no PEIC. Tem distribuição geográfica ampla em países da América do Sul a leste dos Andes, como Bolívia, Brasil, Colômbia, Uruguai, Paraguai e Argentina (IUCN 2010). Contudo, análises moleculares mostraram indícios de que podem existir populações de espécies crípticas sendo tratadas sob esse nome (Heyer et al. 2006).

\section{FAMÍLIA MICROHYLIDAE}

\section{Chiasmocleis leucosticta (Boulenger, 1888) (Figura 3t)}

Chiasmocleis leucosticta é uma espécie fossória e noturna, encontrada no interior de áreas de Mata Atlântica dos Estados de São Paulo a Santa Catarina (Cruz et al. 1997, Frost 2010). Sua reprodução é explosiva e ocorre após chuvas fortes, e os ovos são depositados em poças temporárias em meio a bolhas de ar produzidas pelo casal em amplexo (Haddad \& Hödl 1997). Na Ilha do Cardoso, foi encontrado apenas um indivíduo, na trilha no interior da restinga baixa após uma forte chuva.

A predominância de espécies pertencentes à família Hylidae corrobora o padrão encontrado para todas as localidades da região Neotropical estudadas, desde áreas de Cerrado (e.g. Ribeiro Jr. \& Bertoluci 2009) e do domínio da Mata Atlântica (Duellman 1988, 1999, Heyer et al. 1990, Bertoluci 1998, Bertoluci \& Rodrigues 2002a,b, Canelas \& Bertoluci 2007, Bertoluci et al. 2007a, 2009), incluindo áreas de restinga (Narvaes et al. 2009). A riqueza de espécies do PEIC é comparável à da restinga da Estação Ecológica Juréia-Itatins, Núcleo Arpoador (20 espécies), única área de floresta de restinga até então estudada ao longo de um ciclo anual no estado de São Paulo e que possui a maior riqueza de anuros já registrada para uma localidade desse tipo de ambiente (Narvaes et al. 2009). A maior riqueza de anuros do PEIC em relação à de outras áreas de restinga estudadas ao longo da costa brasileira (RJ, ES e BA) por Rocha et al. (2008), deve-se provavelmente à fisionomia de floresta da vegetação de restinga da ilha (e também da Juréia) e seu menor grau de fragmentação, o que contrasta com a vegetação arbustiva, de estrutura menos complexa, das outras áreas, mais fragmentadas, onde o maior número de espécies (13) foi encontrado na Praia das Neves (ES). A maior complexidade estrutural das restingas paulistas permite a ocorrência de espécies típicas de ambientes florestais.

Nenhuma espécie mostrou-se endêmica da área. O baixo grau de endemismo das restingas, onde apenas cinco espécies de anuros merecem esse status (Carvalho-e-Silva et al. 2000), repete-se em todo o sudeste do Brasil (e.g. Van Sluys et al. 2004, Narvaes et al. 2009), que possui anurofaunas compostas por espécies de distribuição mais ampla no domínio da Mata Atlântica.

A curva de rarefação de espécies (Figura 4) apresentou forte tendência à estabilização. A partir do décimo mês de amostragem, houve certa tendência à estabilização da curva em 15 espécies, de forma que nos outros 15 períodos de amostragens foram acrescidas apenas duas espécies. A riqueza foi estimada em 17,77 (Bootstrap) e 17,96 (Jacknife 1), o que indica que nosso esforço amostral foi suficiente para amostrar praticamente toda a anurofauna da área. De fato, duas novas amostragens em áreas de restinga da Ilha do Cardoso (Pinheiro 2009, Ramos 2010) não acrescentaram nenhuma espécie à nossa lista.
As informações acima revelam a importância da floresta de restinga da Ilha do Cardoso para a manutenção de populações de anuros.

\section{Distribuição espacial}

A Tabela 2 mostra a distribuição espacial das espécies registradas nos sítios reprodutivos amostrados. Somente três espécies (Leptodactylus bokermanni, L. latrans e Scinax alter) foram encontradas em todos os tipos vegetacionais (Restinga Alta, Restinga Baixa, Arbustivo-Arbórea e Herbáceo-Arbustiva) em ambientes abertos degradados ou não, e apenas L. bokermanni apresentou machos em atividade vocal em todos os tipos. O comportamento generalista no uso de habitats mostrado por essas espécies já foi verificado em outras taxocenoses (e.g., Bertoluci \& Rodrigues 2002a, Narvaes et al. 2009), e L. bokermanni comporta-se geralmente como oportunista em termos de local e momento da reprodução (Canelas \& Bertoluci 2007). Aparasphenodon bokermanni foi encontrada apenas na Restinga Alta com alta densidade de bromeliáceas, o que sugere sua associação com essas plantas, como ocorre na outra espécie do gênero (Teixeira et al. 2002).

A análise de agrupamento evidenciou três grupos de espécies em que houve similaridade completa no uso de sítios reprodutivos (Figura 5). Os machos de Hypsiboas albomarginatus e de $H$. faber vocalizaram apenas nos sítios 1, 2 e 4 da Restinga Baixa. Esses sítios retêm água durante apenas parte do ano, oferecendo oportunidade para que os machos de $H$. faber escavem seus ninhos nas margens. Os ninhos protegem os girinos nas fases precoces do desenvolvimento; em fases mais avançadas, os girinos se deslocam até o corpo d'água principal, onde completam a metamorfose (Bertoluci 1991). Itapotihyla langsdorffii, Dendropsophus berthalutzae e Dendropsophus cf. decipiens vocalizaram em corpos d'água temporários (Sítios 1 e 4), um hábito conhecido para as duas primeiras espécies (IUCN 2010). O terceiro grupo é formado por Scinax alter e Physalaemus spiniger, espécies que se reproduzem em lagoas temporárias de áreas abertas ou da borda da floresta ou em locais sujeitos a inundação (IUCN 2010).

As demais espécies apresentaram maiores diferenças no uso dos sítios reprodutivos, corroborando a idéia de que esses ambientes se comportam como fatores limitantes para os anuros (Crump 1974). Isso revela a importância da preservação de corpos d'água de diferentes fisionomias como um fator fundamental para a conservação dos anuros em populações viáveis.

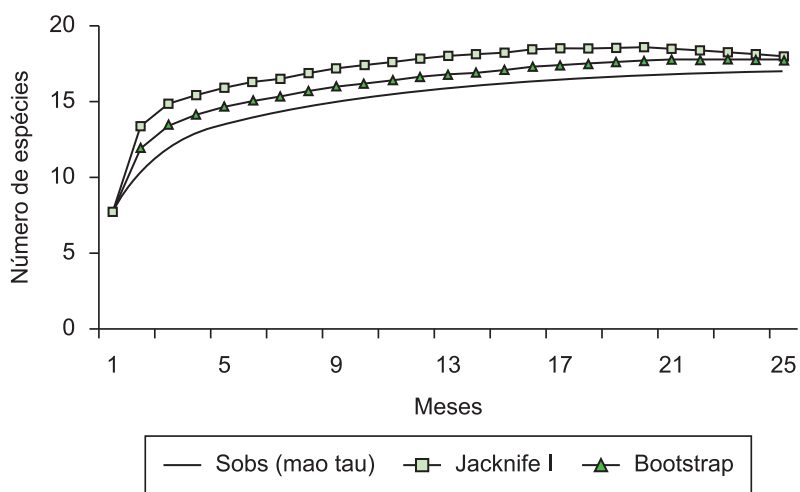

Figura 4. Curva de acumulação de espécies (Sobs) e curvas de riqueza estimada geradas pelos estimadores Jacknife 1 e Bootstrap a partir de 500 aleatorizações ao longo de 25 meses (outubro de 2005 a outubro de 2007) no PEIC, SP.

Figure 4. Species accumulation curve (Sobs) and richness estimators Jacknife 1 and Bootstrap built from 500 randomizations, during 25 months (October 2005 to October 2007) in PEIC. 
Vilela, V.M.F.N. et al

Tabela 2. Distribuição espacial de 15 espécies de anuros em nove sítios reprodutivos do Parque Estadual da Illha do Cardoso (SP). Os sítios 5, 6, 7, 8 e 9 foram amostrados apenas a partir de julho de 2006. V, vocalização; A, presença de adulto (sem vocalização); G, girinos.

Table 2. Spatial distribution of 15 anuran species in nine breeding sites of the Parque Estadual da Ilha do Cardoso (SP). Sites 5, 6, 7, 8 e 9 were sampled only from July 2006. V, calling; A, presence of adult (calling activity not recorded); G, tadpoles.

\begin{tabular}{|c|c|c|c|c|c|c|c|c|c|}
\hline \multirow{2}{*}{$\begin{array}{c}\text { Tipo de } \\
\text { vegetação }\end{array}$} & \multirow{2}{*}{$\begin{array}{c}\text { Restinga } \\
\text { alta }\end{array}$} & \multicolumn{6}{|c|}{$\begin{array}{c}\text { Restinga } \\
\text { baixa }\end{array}$} & \multirow{2}{*}{$\begin{array}{c}\text { Arbustiva- } \\
\text { arbórea } \\
\text { Sítio } 3\end{array}$} & \multirow{2}{*}{$\begin{array}{c}\text { Herbácea- } \\
\text { arbustiva } \\
\text { Sítio } 7\end{array}$} \\
\hline & & Sítio 1 & Sítio 2 & Sítio 4 & Sítio 5 & Sítio 6 & Sítio 8 & & \\
\hline Leptodactylus latrans & $\mathrm{A}$ & $\mathrm{G}$ & $\mathrm{V}$ & A & $\mathrm{A}$ & $\mathrm{A}$ & - & $\mathrm{A}$ & V \\
\hline Scinax argyreornatus & A & $\mathrm{V}$ & A & V & A & A & A & $\mathrm{V}$ & - \\
\hline Scinax sp.1 (aff. alter) & A & V & $\mathrm{V}$ & V & - & A & V & V & V \\
\hline Physalaemus spiniger & - & V & $\mathrm{V}$ & V & - & - & - & $\mathrm{V}$ & V \\
\hline Rhinella ornata & A & V & A & A & - & V & $\mathrm{A}$ & - & - \\
\hline Leptodactylus bokermanni & $\mathrm{V}$ & - & $\mathrm{V}$ & - & - & V & - & V & V \\
\hline Hypsiboas albomarginatus & - & V & $\mathrm{V}$ & V & A & - & - & - & - \\
\hline Hypsiboas faber & A & V & V & V & - & - & - & - & - \\
\hline Dendrophryniscus leucomystax & $\mathrm{V}$ & - & - & - & - & - & A & V & - \\
\hline Scinax sp.2 (aff. perpusillus) & - & - & - & A & - & - & V & V & - \\
\hline Itapotihyla langsdorffii & - & V & A & V & - & - & - & - & - \\
\hline Dendropsophus cf. decipiens & - & V & A & V & - & - & - & - & - \\
\hline Dendropsophus berthalutzae & - & V & - & V & - & - & - & - & - \\
\hline Eleutherodactylus binotatus & - & - & - & - & A & - & - & - & - \\
\hline Aparasphenodon bokermanni & A & - & - & - & - & - & - & - & - \\
\hline Número de espécies & 8 & 10 & 10 & 11 & 4 & 5 & 5 & 7 & 4 \\
\hline
\end{tabular}

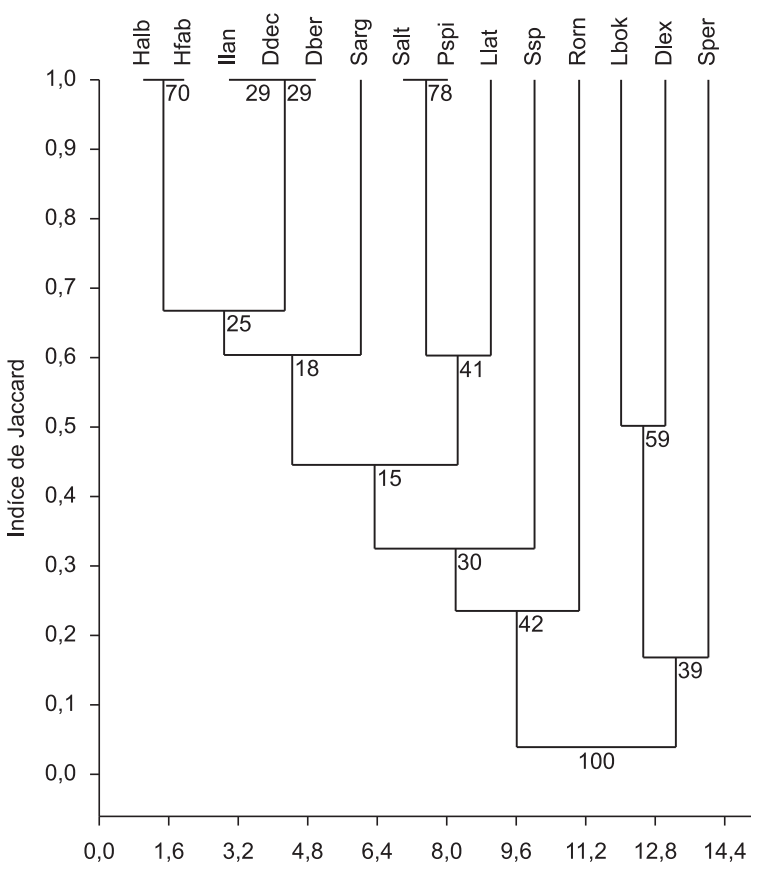

Figura 5. Análise de agrupamento de 14 espécies de anuros com base em sua ocorrência em nove sítios reprodutivos do Parque Estadual da Ilha do Cardoso (SP). Legenda: Halb (Hypsiboas albomarginatus), Hfab (H. faber), Ilan (Itapotihyla langsdorffii), Ddec (Dendropsophus cf. decipiens), Dber (Dendropsophus berthalutzae), Sarg (S. argyreornatus), Salt (Scinax sp.1 (aff. alter)), Pspi (Physalaemus spiniger), Llat (L. latrans), Ssp (Scinax sp.3 (gr. rizibilis)), Rorn (Rhinella ornata), LboK (Leptodactylus bokermanni), Dlex (Dendrophryniscus leucomystax), Sper (Scinax sp.2 (aff. perpusillus)).

Figure 5. Cluster analyses of 14 anuran species based on their occurrence in nine breeding sites of the Parque Estadual da Ilha do Cardoso (SP). Legend: Halb (Hypsiboas albomarginatus), Hfab (H. faber), Ilan (Itapotihyla langsdorffii), Ddec (Dendropsophus cf. decipiens), Dber (Dendropsophus berthalutzae), Sarg (S. argyreornatus), Salt (Scinax sp.1 (aff. alter)), Pspi (Physalaemus spiniger), Llat (L. latrans), Ssp (Scinax sp.3 (gr. rizibilis)), Rorn (Rhinella ornata), Lbok (Leptodactylus bokermanni), Dlex (Dendrophryniscus leucomystax), Sper (Scinax sp.2 (aff. perpusillus)).

\section{Agradecimentos}

Os autores agradecem à FAPESP pelo apoio financeiro (processos 04/15938-5 e 99/09635-0), ao CNPq pela bolsa de Produtividade em Pesquisa concedida a JB, a Vanessa K. Verdade pela ajuda na identificação de algumas espécies e a Hussan Zaher pelo acesso à coleção herpetológica MZUSP. Ao IBAMA pela licença de coleta ( ${ }^{\circ}$ 430/05), ao IFSP pela permissão de acesso ao Parque Estadual da Ilha do Cardoso, a Sarah C. P. Pinheiro, José Wagner Ribeiro Junior, Henrique O. Sawakuchi, Shirley Fameli, Paula C. Lopes, Bruno H. C. Cavichioli, Gabriel L. Brejão, Pablo G. Soares, Carolina F. Esteves, Fábio Crocco, Leonardo, Julia, Michelle C. P. Bordini, Giselle N. C. Melendez e Michele A. Lochosk pelo auxílio nos trabalhos de campo, e a Célio Haddad pelo acesso à coleção de anuros CFBH (UNESP).

\section{Referências Bibliográficas}

ALVES-SILVA, R. \& SILVA, H.R. 2009. Life in bromeliads: reproductive behaviour and the monophyly of the Scinax perpusillus species group (Anura: Hylidae). J. Nat. Hist. 43:205-217.

ANGULO, A., COCROFT, R.B. \& REICHLE, S. 2003. Species identity in the genus Adenomera (Anura: Leptodactylidae) in southeastern Peru. Herpetologica 59:490-503.

ARAÚJO, D.S.D. \& LACERDA, L.D. 1987. A natureza da restinga. Ci. Hoje 6(33):42-48.

ARAUJO, D.S.D., SCARANO, F.R., SÁ, C.F.C., KURTZ, B.C., ZALUAR, H.L.T., MONTEZUMA, R.C.M. \& OLIVEIRA, R.C. 1998. Comunidades vegetais do Parque Nacional da Restinga de Jurubatiba. In Ecologia das lagoas costeiras do Parque Nacional da Restinga de Jurubatiba e do Município de Macaé, RJ (F.A. Esteves, ed.). Universidade Federal do Rio de Janeiro, Rio de Janeiro, p.39-62.

ARZABE, C. \& LOEBMANN, D. 2006. Amphibian, Hylidae, Itapotihyla langsdorffii: distribution extension. Check List 2(2):33-34.

BALDISSERA Jr., F.A.; CARAMASCHI, U. \& HADDAD, C.F.B. 2004. Review of the Bufo crucifer species group, with descriptions of two new related species (Amphibia, Anura, Bufonidae). Arqu. do Museu Nac. 62(3):255-282.

BASTOS, R.P. \& POMBAL Jr., J.P. 1996. A new species Hyla (Anura: Hylidae) from eastern Brazil. Amphibia-Reptilia 17:325-31. 
BERTOLUCI, J. 1991. Partição de recursos associada à atividade reprodutiva em uma comunidade de anuros (Amphibia) de Mata Attântica. Dissertação de Mestrado, Universidade de São Paulo, São Paulo. 118p.

BERTOLUCI, J. 1998. Annual patterns of breeding activity in Atlantic Rainforest anurans. J. Herpetol. 32:607-611.

BERTOLUCI, J. \& RODRIGUES, M.T. 2002a. Utilização de hábitats reprodutivos e micro-hábitats de vocalização em uma taxocenose de anuros (Amphibia) da Mata Atlântica do sudeste do Brasil. Pap. Avulsos Zool. 42(11):287-297.

BERTOLUCI, J. \& RODRIGUES, M.T. 2002b. Seasonal patterns of breeding activity of Atlantic rainforest anurans at Boracéia, southeastern Brazil. Amph-Rept. 23(2):161-167.

BERTOLUCI, J., BRASSALOTI, R.A., RIBEIRO Jr., J.W., VILELA, V.M.F.N. \& SAWAKUCHI, H.O. 2007a. Species composition and similarities among anuran assemblages of forest sites in southeastern Brazil. Sci. Agric. 64(4):364-374.

BERTOLUCI, J., BRASSALOTI, R.A., SAWAKUCHI, H.O., RIBEIRO Jr., J.W.\& WOEHL Jr., G. 2007b. Defensive behaviour with stiff-legged posture in the Brazilian tree toads Dendrophryniscus brevipollicatus and D. leucomystax (Anura, Bufonidae). Alytes 25(1-2):38-44.

BERTOLUCI, J., CANELAS, M.A.S., EISEMBERG, C.C., PALMUTI, C.F.S \& MONTINGELLI, G.G. 2009. Herpetofauna da Estação Ambiental de Peti, um fragmento de Mata Atlântica do estado de Minas Gerais, sudeste do Brasil. Biota Neotrop. 9(1):147-155.

BOKERMANN, W.C.A. 1967. Notas sobre cantos nupciais de anfíbios brasileiros. I. Anais da Academia Brasileira de Ciências 39:441-446.

BRITTO-PEREIRA, M.C., CERQUEIRA, R., SILVA, H.R. \& CARAMASCHI, U. 1988a. Anfíbios anuros da restinga de Barra de Maricá, RJ: levantamento e observações preliminares sobre a atividade reprodutiva das espécies registradas. In Anais do VI Seminário Regional de Ecologia. Universidade de São Carlos, São Carlos, p.295-306.

BRITTO-PEREIRA, M.C., CERQUEIRA, R., SILVA, H.R. \& CARAMASCHI, U. 1988b. Utilização de Neoregelia cruenta (Bromeliaceae) como abrigo diurno por anfíbios anuros na Restinga de Maricá, Rio de Janeiro. In Anais do VI Seminário Regional de Ecologia. Universidade de São Carlos, São Carlos, p.307-818.

CANELAS, M.A.S. \& BERTOLUCI, J. 2007. Anurans of the Serra do Caraça, southeastern Brazil: species composition and phenological patterns of calling activity. Iheringia-S. Zool. 97(1):21-26.

CARVALHO-E-SILVA, S.P. \& CARVALHO-E-SILVA, A.M.P.T. 1998. Aspects of the biology and description of the larvae of Scinax argyreornatus and S. humilis (Amphibia: Anura: Hylidae). Revue Fr. Aquariol. 25:47-52.

CARVALHO-E-SILVA, S.P., IZECKSOHN, E. \& CARVALHO-E-SILVA, A.M.P.T. 2000. Diversidade e ecologia de anfíbios em restingas do sudeste brasileiro. In Ecologia de restingas e lagoas costeiras (F.A. Esteves \& L.D. Lacerda, eds). NUPEM; UFRJ, Macaé, p.89-97.

COLWELL, R.K. 2005. EstimateS: Statistical estimation of species richness and shared species from samples. Version 7.5.0. User's Guide and application published at: http://purl.oclc.org/estimates (último acesso em 18/02/2009)

CRUMP, M.L. 1974. Reproductive strategies in a tropical anuran community. Misc. Publ. Mus. Nat. Hist. Univ. Kansas 61:1-68.

CRUMP, M.L. \& SCOTT Jr., N.J. 1994. Visual encounter surveys. In Measuring and monitoring biological diversity: standard methods for amphibians (W.R. Heyer, M.A. Donnelly, R.W. McDiarmid, L.A.C. Hayek \& M.S. Foster (eds.). Smithsonian Institution Press, p.84-92.

CRUZ, C.A.G., CARAMASCHI, U. \& IZECKSOHN, E. 1997. The genus Chiasmocleis Méhelÿ, 1904 (Anura, Microhylidae) in the Atlantic Rain Forest of Brazil, with description of three new species. Alytes 15:49-71.

DEIQUES, C.H., STAHNKE, L.F., REINKE, M. \& SCHMITT, P. 2007. Guia ilustrado - anfíbios e répteis do Parque Nacional de Aparados da Serra, Rio Grande do Sul, Santa Catarina, Brasil. USEB, Pelotas, 120p.

DIXO, M. \& VERDADE, V.K. 2006. Herpetofauna de serrapilheira da Reserva Florestal de Morro Grande, Cotia (SP). Biota Neotrop. 6(2): http://www. biotaneotropica.org.br/v6n2/pt/abstract?article+bn00806022006 (último acesso em 10/02/2009).
DUELLMAN, W.E. 1988. Patterns of species diversity in anuran amphibians in the American Tropics. Ann. Missouri Bot. Gard. 75(1):79-104.

DUELLMAN, W.E. 1999. Patterns of distribution of amphibians. Johns Hopkins University Press, Baltimore.

FRANCO, A.C., VALERIANO, D.M., SANTOS, F.M., HAY, J.D., HENRIQUES, R.P.B. \& MEDEIROS, R.A. 1984. Os microclimas das zonas de vegetação da praia da restinga de Barra de Maricá, Rio de Janeiro. In Restingas: origem, estrutura e processos. (L.D. Lacerda, D.S.D. Araujo, R. Cerqueira \& B. Turcq, orgs.). CEUFF, Niterói, p.413-425.

FREIRE, M.S.B. 1990. Levantamento florístico do Parque Estadual das Dunas de Natal, Acta Bot. Bras. 4(1):41-59.

FROST, D.R. 2010. Amphibian species of the world: an online reference. Electronic database accessible at http://research.amnh.org/herpetology/ amphibia (último acesso em 01/07/2010).

FUNARI, F.L., STRUFFALDI-DE-VUONO, Y. \& SALUM, S.T. 1987. Balanço hídrico de duas áreas de Mata Atlântica: Reserva Biológica de Paranapiacaba e Parque Estadual da Ilha do Cardoso (São Paulo). In Anais do VI Congresso da Sociedade Botânica de São Paulo, p. 95-101.

GIASSON, L.O.M. \& HADDAD, C.F.B. 2006. Social interactions in Hypsiboas albomarginatus (Anura: Hylidae) and the significance of acoustic and visual signals. J. Herpetol. 40:171-180.

GOTELLI, N.J. \& COLWELL, R.K. 2001. Quantifying biodiversity: procedures and pitfalls in the measurement and comparison of species richness. Ecol. Lett. 4(4):379-391.

HARTMANN, M.T., GIASSON, L.O.M., HARTMANN, P.A. \& HADDAD, C.F.B. 2005. Visual communication in Brasilian species of anurans from the Atlantic forest. J. Nat. Hist. 39:1675-1685

HADDAD, C.F.B. \& HÖDL, W. 1997. New reproductive mode in Anurans: bubble nest in Chiasmocleis leucosticta (Microhylidae). Copeia 1997(3):585-588.

HADDAD, C.F.B. \& POMBAL Jr., J.P. 1998. Redescription of Physalaemus spiniger (Anura: Leptodactylidae) and description of two new reproductive modes for anurans. Journal of Herpetology 32(4):557-565.

HADDAD, C.F.B., GIOVANELLI, J., GIASSON, L.O. \& TOLEDO, L.F. 2005. Guia Sonoro dos Anfíbios Anuros da Mata Atlântica. CD.

HEYER, W.R. 1973. Systematics of the marmoratus group of the frog genus Leptodactylus (Amphibia, Leptodactylidae). Smith. Contrib. Sci. 251:1-50.

HEYER, W.R., CARAMASCHI, U. \& SÁ, R.O. 2006. Rana ocellata Linnaeus, 1758 (currently Leptodactylus ocellatus; Amphibia, Anura): proposed conservation of usage of the specific name by the designation of a neotype. Bull. Zool. Nomenclature 63(3):184-186.

HEYER, W.R., RAND, A.S., CRUZ, C.A.G., PEIXOTO, O.L. \& NELSON, C.E. 1990. Frogs of Boracéia. Arq. Zool. 31(4):231-410.

INTERNATIONAL UNION FOR CONSERVATION OF NATURE - IUCN. 2010. IUCN Red List of Threatened Species. Version 2010.2. www. iucnredlist.org (último acesso em 09/08/2010).

IZECKSOHN, E. 1968. Nova espécie de Dendrophryniscus do Estado do Rio de Janeiro. Rev. Bras. Biol. 28:357-362.

IZECKSOHN, E. \& CARVALHO-E-SILVA, S.P. 2001. Anfíbios do município do Rio de Janeiro. Editora UFRJ, Rio de Janeiro.

IZECKSOHN, E. \& CRUZ, C.A.G. 1972. Notas sobre os girinos de Dendrophryniscus leucomystax Izecksohn e D. brevipollicatus Espada (Amphibia, Anura, Bufonidae). Arq. Univ. Fed. Rural Rio J. 2(2):63-69.

KOKUBUM, M.N.C. 2008. Ecologia reprodutiva e diversidade acústica em espécies de Leptodactylus do grupo marmoratus (Anura: Leptodactylidae). Tese de Doutorado, Universidade de Brasília, ICB, Brasília, DF. 315p.

LACERDA, L.D., ARAÚJO, D.S.D. \& MACIEL, N.C. 1993. Dry coastal ecosystems of the tropical Brazilian coast. In Dry coastal-ecosystems: Africa, Asia, Oceania (E. Van der Maarel, ed.). Elsevier, Amsterdam, p. $477-493$.

LOEBMANN, D. 2005. Guia Ilustrado - os anfíbios da região costeira do extremo sul do Brasil. USEB, Pelotas.

LUTZ, B. 1973. Brazilian species of Hyla. University of Texas Press, Austin.

MANTOVANI, W. 2003. A degradação dos biomas brasileiros. In Patrimônio Ambiental Brasileiro. Uspiana: Brasil 500 anos. (W.C. Ribeiro, org.). Editora da Universidade de São Paulo; Imprensa Oficial do Estado de São Paulo, São Paulo. 
MARTINS, M. \& HADDAD, C.F.B. 1988. Vocalizations and reproductive behaviour in the Smith frog, Hyla faber Wied (Amphibia : Hylidae). Amph-Rept. 9:49-60.

NARVAES, P., BERTOLUCI, J. \& RODRIGUES, M.T. 2009. Composição, uso de hábitat e estações reprodutivas das espécies de anuros da floresta de restinga da Estação Ecológica Juréia-Itatins, sudeste do Brasil. Biota Neotropica 9(2):117-123.

NOFFS, M.S. \& BAPTISTA-NOFFS, C.J. 1982. Mapa da vegetação do Parque Estadual da Ilha do Cardoso-SP: as principais formações. Rev. Inst. Florest. 16(1):620-622.

NUNES, I. 2008. Revisão taxonômica do complexo de espécies de $S$. cuspidatus (A. Lutz, 1925) e Scinax alter (B. Lutz, 1973) (Amphibia, Anura, Hylidae). Dissertação de Mestrado, Universidade Federal do Rio de Janeiro.

OLIVEIRA, F.B. \& NAVAS, C.A. 2004. Plant selection and seasonal patterns of vocal activity in two populations of the bromeligen treefrog Scinax perpusillus (Anura: Hylidae). J. Herpetol. 38(3):331-339.

OLIVEIRA, M.G.N. \& ROCHA, C.F.D. 1997. O efeito da complexidade da bromélia-tanque Neoregelia cruenta (R. Graham) L.B. Smith sobre a comunidade animal associada. Bromélia 4(1):13-22.

PEIXOTO, O.L. 1987. Caracterização do grupo "perpusilla" e reavaliação da posição taxonômica de Ololygon perpusilla perpusilla e Ololygon perpusilla v-signata. Arq. Univ. Fed. Rural R. Jan. 10(1-2):37-49.

PEIXOTO, O.L. 1995. Associação de anuros a bromeliáceas na mata Atlântica. Rev. Univ. Rural - Sér. Ciênc. da Vida 17(2):75-83.

PINHEIRO, S.C.P. 2009. Anurofauna de serapilheira de diferentes formações vegetais ao longo de um gradiente altitudinal no Parque Estadual da Ilha do Cardoso, município de Cananéia, SP. Dissertação de Mestrado, Universidade de São Paulo. 110p.

POMBAL Jr., J.P. \& GORDO, M. 2004. Anfíbios anuros da Juréia. In Estação Ecológica Juréia-Itatins: ambiente físico, flora e fauna (O.A.V. Marques \& W. Duleba, eds.). Editora Holos, Ribeirão Preto, p.243-256.

RAMOS, J.Z.P. 2010. Estudo comparativo da taxocenose de anuros de quatro Municípios do Lagamar Paulista. Tese de Doutorado, Universidade Estadual Paulista Júlio de Mesquita Filho, Rio Claro, SP. 136p.

RIBEIRO Jr., J.W. \& BERTOLUCI, J. 2009. Anuros do cerrado da Estação Ecológica e da Floresta Estadual de Assis, sudeste do Brasil. Biota Neotrop. 9(1):207-216

ROCHA, C.F.D., COGLIATTI-CARVALHO, L., ALMEIDA, D.R. \& FREITAS, A.F.N. 1997. Bromélias: ampliadoras da biodiversidade. Bromélia 4(1):7-10.

ROCHA, C.F.D., HATANO, F H., VRCIBRADIC, D. \& VAN SLUYS, M. 2008. Frog species richness and B-diversity in coastal Brazilian restinga habitats. Braz. J. Biol. 68(1):109-115.

SANTOS, A.J. 2003. Estimativas de riqueza em espécies. In Métodos de estudos em biologia da conservação e manejo da vida silvestre (L. Cullen Jr., R. Pudran \& C. Valladares-Pádua, eds.). Editora da UFPR, Curitiba, p.19-41

SCHINEIDER, J.A.P. \& TEIXEIRA, R.L. 2001. Relationship between anuran amphibians and bromeliads of the sandy coastal plain of Regência, Linhares, Espírito Santo, Brazil. Iheringia S. Zool. 91(1):41-48.
SCOTT Jr., N.J., \& WOODWARD, B.D. 1994. Surveys at breeding sites. In Measuring and monitoring biological diversity: standard methods for amphibians (W.R. Heyer, M.A. Donnelly, R.W. McDiarmid, L.A.C. Hayek \& M.S. Foster (eds.). Smithsonian Institution Press, p.118-124.

SILVA, H.R. \& ALVES-SILVA, R. 2008. New coastal and insular species of the bromeligenous Scinax perpusillus group, from the State of Rio de Janeiro, Brazil (Anura, Hylidae). Zootaxa 1914:34-44.

SILVA, H.R., CARVALHO, A.L.G. \& BITTENCOURT-SILVA, G.B. 2008. Frogs of Marambaia: a naturally isolated Restinga and Atlantic Forest remnant of southeastern Brazil. Biota Neotrop. 8(4):167-174.

SILVANO, D.L. \& PIMENTA, B.V.S. 2001. Geografic distribution. Scinax argyreornatus. Herpetol. Rev. 32:273.

SILVA-SOARES, T., HEPP, F., COSTA, P.N., LUNA-DIAS, C., GOMES, M.R., CARVALHO-E-SILVA, A.M.P.T. \& CARVALHO-E-SILVA, S.P. 2010. Anfíbios anuros da RPPN Campo Escoteiro Geraldo Hugo Nunes, Município de Guapimirim, Rio de Janeiro, Sudeste do Brasil. Biota Neotrop. 10(2):225-233.

TEIXEIRA, R.L. 2001. Comunidade de lagartos da Restinga de Guriri, São Mateus - ES, Sudeste do Brasil. Atlântica 23:77-94.

TEIXEIRA, R.L. \& VRCIBRADIC, D. 2004. Ecological aspects of Scinax argyreornatus (Anura, Hylidae) from a cacao plantation Espirito Santo state, southeastern Brazil. Bol. Mus. Mello Leitão 17:35-43.

TEIXEIRA, R.L., SCHINEIDER, J.A.P. \& ALMEIDA, G.I. 2002. The occurrence of amphibians in bromeliads from a southeasthern Brazilian Restinga habitat, with special reference to Aparasphenodon brunoi (Anura, Hylidae). Braz. J. Biol. 62(2):263-268.

THOMÉ, M.T.C., ZAMUDIO, K.R., GIOVANELLI, J.G.R., HADDAD, C.F.B., BALDISSERA Jr., F.A. \& ALEXANDRINO, J. 2010. Phylogeography of endemic toads and post-Pliocene persistence of the Brazilian Atlantic Forest. Mol. Phylogen. Evol. 55:1018-1031.

VAN SLUYS, M., ROCHA, C.F.D., HATANO, F.H., BOQUIMPANIFREITAS, L. \& MARRA, R.V. 2004. Anfíbios da Restinga de Jurubatiba: composição e história natural. In Pesquisas de longa duração na restinga de Jurubatiba: ecologia, história natural e conservação (C.F.D. Rocha, F.A. Esteves \& F.R. Scarano, eds.). RiMa, São Carlos, SP, p.165-318.

VAZ-FERREIRA, R. \& GERHAU, A. 1975. Comportamiento epimelético de la rana común Leptodactylus ocellatus (L.) (Amphibia, Leptodactylidae) I. Atención de la cría y actividades alimentarias y agresivas relacionadas. Physis 34(88):1-14.

WALTER, H., HARNICKEL, E. \& MUELLER-DOMBOIS, D. 1975. Climate diagram maps of the individual continents and the ecological climate regions of the Earth. Supplement to the Vegetation Monographs. Springer-Verlag, Berlin.

WOEHL Jr., G. \& WOEHL, E.N. 2003. Geographic distribution note: Aparasphenodon bokermanni. Herpetol. Rev. 34:379.

ZIMMERMAN, B.L. 1994. Audio strip transects. In Measuring and monitoring biological diversity: standard methods for amphibians (W.R. Heyer, M.A. Donnelly, R.W. McDiarmid, L.A.C. Hayek \& M.S. Foster (eds.). Smithsonian Institution Press, p.92-96. 


\section{Apêndice}

Apêndice I. Material examinado depositado na Coleção Herpetológica do Laboratório de Zoologia de Vertebrados da ESALQ-USP, acrônimo VESALQ (números de tombo).

Appendix I. Material examined (deposited in the herpetological collection of the Laboratório de Zoologia de Vertebrados da ESALQ-USP, acronym VESALQ; voucher numbers).

Aparasphenodon bokermanni (409), Chiasmocleis leucosticta (462), Dendrophryniscus leucomystax (370), Dendropsophus aff. decipiens (384, 386, 402, 428), Dendropsophus berthalutzae (389), Haddadus binotatus (357, 372, 382, 431), Hypsiboas albomarginatus (383), Itapotihyla langsdorffi (465), Leptodactylus bokermanni (394, 433, 441), Leptodactylus latrans (429), Physalaemus spiniger (380, 393, 410, 411, 432), Rhinella ornata (430, 463), Scinax argyreornatus (385, 401, 440), Scinax sp.1 (aff. alter) (387, 388), Scinax sp.2 (aff. perpusillus) (PEIC 400, 439), Scinax sp.3 (gr. rizibilis) (373, 408, 427, 464). 